Research Article

\title{
Third generation cephalosporin-resistance in Klebsiella pneumoniae isolates: an emerging threat
}

\author{
Saroj Kothari $^{\mathrm{a}, *}$, Vaibhav Mishrab ${ }^{\mathrm{b}}$, Neelima Ranjan ${ }^{\mathrm{b}}$, Alok Singh ${ }^{\mathrm{a}}$
}

${ }^{a}$ Department of Pharmacology, G.R. Medical College, Gwalior, M.P., India

${ }^{\mathrm{b}}$ Department of Microbiology, G.R. Medical College, Gwalior, M.P., India

Received: 19 November 2012

Revised: 13 December 2012

Accepted: 14 December 2012

*Correspondence to:

Dr. Saroj Kothari

Email:

saroj.kothari@rediffmail.com

\begin{abstract}
Background: Newer generation cephalosporin-resistance among Klebsiella pneumoniae organisms has increased recently. Present study is undertaken to find incidence, antimicrobial susceptibility and prevalence of extended spectrum beta-lactamase (ESBL) in K. pneumoniae isolates in a tertiary care hospital.

Methods: Prospective study was carried out between June to December 2011. Samples of pus, blood, urine, cerebro-spinal fluid, stool, peritoneal, pleural and synovial fluid were collected from indoor and outdoor patients for isolation and antimicrobial susceptibility pattern of $K$. pneumoniae in the department of microbiology, G.R. Medical College Gwalior, M.P. Ceftazidime resistant $K$. pneumoniae were subjected to Phenotypic Confirmatory Disc Diffusion Test (PCDDT) and Double Disc Synergy Test (DDST) for detection of ESBL.

Results: Out of 2480 samples collected a total of $530 \mathrm{~K}$. pneumoniae were isolated and subjected to antimicrobial susceptibility. Antibiotic sensitivity to imipenem, cefoperazone, amikacin and ofloxacin were 82, 74, 73 and 72\% respectively whereas sensitivity to ceftizoxime, ceftriaxone cefotaxime, ceftazidime ranged between $47-50 \%$. K. pneumoniae were found to be resistant to ampicillin, co-trimoxazole, doxycycline and gentamicin, by $91,82,54$ and $50 \%$ respectively. Among third generation cephalosporins K. pneumoniae were least sensitive (47\%) to ceftazidime. About 33 and $32 \%$ of the ceftazidime resistant strains were found to be ESBL positive by PCDDT and DDST respectively.

Conclusions: This study has shown that prevalence of ESBL producing $K$. pneumoniae is the most important reason for increased resistance to third generation cephalosporins. There is need to carry out tests for detection of ESBL producing bacteria routinely.
\end{abstract}

Keywords: Antimicrobial-resistance, Clinical isolates, Klebsiella pneumoniae, Third generation- cephalosporins

\section{INTRODUCTION}

A variety of nosocomial and community acquired infections such as pneumonia, urinary tract infections, septicemia, soft tissue infections are caused by $K$. pneumoniae, one of the most deadly pathogen of enterobacteriaceae group. ${ }^{1}$ The emergence of multidrug resistance among gram negative bacteria from the genus Klebsiella has increased. Several strains of Klebsiella which demonstrated similarities in DNA homology are known. These are (1) Klebsiella pneumoniae, (2) Klebsiella ozaenae, (3) Klebsiella rhinoscleromatis, (4) Klebsiella oxytoca, (5) Klebsiella planticola, (6) Klebsiella terrigena, and (7) Klebsiella ornithinolytica. Since $K$. pneumoniae species is most prevalent in hospital acquired infections hence is medically most important. These bacteria may spread horizontally among patients in a particular department by environmental vectors. ${ }^{2}$ Newer cephalosporins, fluoroquinolones, aminoglycosides and carbapenems are the class of drugs most effective for the treatment of infections caused by $K$. pneumoniae. Rising resistance to these drugs is a notable global threat. ${ }^{3-5}$ One of the reason for development of resistance to third generation cephalosporins is production of extended spectrum beta lactamase (ESBL) enzyme which hydrolyses oxyimino-beta-lactam in third generation cephalosporins like cefotaxime, ceftriaxone, ceftazidime and ceftizoxime. ${ }^{6}$ The incidence of ESBL-producing strains among clinical $K$. pneumoniae isolates have steadily increased over the past years and it varies from 
institution to institution. ${ }^{7}$ Therefore present study is undertaken to evaluate incidence, antimicrobial susceptibility and prevalence of ESBL in K. pneumoniae isolates from different clinical samples in a tertiary care hospital.

\section{METHODS}

\section{Sample collection and identification of $K$. pneumoniae}

Prospective study was carried out between June to December 2011. Samples of pus, blood, urine, cerebrospinal fluid, stool, peritoneal, pleural and synovial fluid were collected from indoor and outdoor patients for isolation and antimicrobial susceptibility pattern of $K$. pneumoniae in the department of Microbiology, G. R. Medical College, Gwalior, (M.P.) These samples were inoculated on Mac Conkey's agar and nutrient agar followed by the identification of the isolates based on their cultural characteristics and their reactions in standard biochemical tests. 8 In case of blood sample blood was incubated at $37^{\circ} \mathrm{C}$ overnight in Brain Heart Infusion broth.

\section{Antimicrobial agents}

Isolated $K$. pneumoniae were tested for antimicrobial susceptibility by the Kirby bauer disc diffusion technique ${ }^{9}$ according to the Clinical and Laboratory Standard Institute (CLSI) guidelines on Muller Hinton agar by paper disks impregnated with antibiotics (Span Diagnostics Limited, Surat, India): Penicillins: ampicillin $10 \mu \mathrm{g}$, Cephalosporins: cefoperazone $75 \mu \mathrm{g}$, ceftriaxone $30 \mu \mathrm{g}$, ceftazidime $30 \mu \mathrm{g}$, cefotaxime $30 \mu \mathrm{g}$, ceftizoxime $30 \mu \mathrm{g}$, Carbapenems: imipenem $10 \mu \mathrm{g}$, Aminoglycosides: amikacin $30 \mu \mathrm{g}$, gentamicin $10 \mu \mathrm{g}$, Quinolones: ofloxacin $5 \mu \mathrm{g}$, levofloxacin $5 \mu \mathrm{g}$, ciprofloxacin $5 \mu \mathrm{g}$, Tetracyclines: doxycycline $30 \mu \mathrm{g}$ and co-trimoxazole $25 \mu \mathrm{g}$.

\section{Detection of Extended- spectrum beta-lactamase (ESBL) production}

\section{Phenotypic Confirmatory Disc Diffusion Test (PCDDT)}

Lawn culture of the organism was made and 3rdgeneration cephalosporin: ceftazidime $(30 \mu \mathrm{g})$ disc and ceftazidime + clavulanic acid $(30 \mu \mathrm{g}+10 \mu \mathrm{g})$ disc were placed with $25 \mathrm{~mm}$ apart. An isolate showing increase of $\geq 5 \mathrm{~mm}$ in zone of inhibition for ceftazidime + clavulanic acid compared to ceftazidime was confirmed as ESBL producer. ${ }^{10}$

\section{Double Disc Synergy Test (DDST)}

The isolated colonies were inoculated in peptone water at $37^{\circ} \mathrm{C}$ for 2-6 h. The turbidity was adjusted to 0.5 McFarland standards and lawn culture was made on
Mueller-Hinton agar using sterile swab. Amoxicillin + Clavulanic acid disc $(20 / 10 \mu \mathrm{g})$ was placed in the centre of plate. Both side of Amoxicillin + Clavulanic acid disc, a disc of cefotaxime $(30 \mu \mathrm{g})$ and ceftazidime $(30 \mu \mathrm{g})$ were placed with centre to centre distance of $15 \mathrm{~mm}$ to centrally placed disc. The plate was incubated at $37^{\circ} \mathrm{C}$ overnight. ESBL production was interpreted as the $3 \mathrm{rd}-$ generation cephalosporin disc inhibition was increased towards the Amoxicillin + Clavulanic acid disc or if neither discs were inhibitory alone but bacterial growth was inhibited where the two antibiotics were diffused together. ${ }^{11}$

\section{RESULTS}

\section{Incidence of K. pneumoniae in clinical samples}

Out of 2480 samples collected, a total of $530 \mathrm{~K}$. pneumoniae were isolated. Hospital prevalence of $K$. pneumoniae was found to be $21 \%$. Among these 530 microorganisms isolated and studied $66 \%$ were from the indoor and $34 \%$ from outdoor samples. The sample wise prevalence of $K$. pneumoniae was $31,21,19,18$ and $15 \%$ from blood, pus, urine, cerebrospinal fluid and miscellaneous (include pleural, peritoneal, synovial fluid and stool) respectively (Table 1 ).

Table 1: Sample wise distribution of $K$. pneumoniae isolates.

\begin{tabular}{|lllcl|}
\hline $\begin{array}{l}\text { Type of } \\
\text { Sample }\end{array}$ & $\begin{array}{l}\text { No. of } \\
\text { samples }\end{array}$ & $\begin{array}{l}\text { Indoor } \\
\text { isolates }\end{array}$ & $\begin{array}{l}\text { Outdoor } \\
\text { isolates }\end{array}$ & $\begin{array}{l}\text { Total } \\
\text { isolates }\end{array}$ \\
\hline Pus & 888 & 65 & 124 & 189 \\
\hline Urine & 812 & 82 & 76 & 158 \\
\hline Blood & 349 & 99 & 8 & 107 \\
\hline CSF & 356 & 63 & 2 & 65 \\
\hline Miscellaneous & 75 & 6 & 5 & 11 \\
\hline Total & $\mathbf{2 4 8 0}$ & $\mathbf{3 1 5}$ & $\mathbf{2 1 5}$ & $\mathbf{5 3 0}$ \\
\hline
\end{tabular}

\section{Antimicrobial susceptibility pattern of K. pneumoniae isolates}

K. pneumoniae isolated from different samples showed antimicrobial sensitivity range to imipenem $72-94 \%$, cefoperazone $69-90 \%$, amikacin $67-78 \%$, ofloxacin $55-$ $89 \%$, levofloxacin 44-67\%, ciprofloxacin 42-69\%, gentamicin $35-64 \%$, ceftizoxime $43-54 \%$, ceftriaxone $40-$ $54 \%$, ceftazidime $30-64 \%$, Cefotaxime $32-60 \%$. Antibiotic resistance of $K$. pneumoniae ranged between $87-95 \%$ to ampicillin, $67-91 \%$ to co-trimoxazole, $39-65 \%$ to gentamicin and $37-61 \%$ to doxycycline (Table 2 ). 
Table 2: Antibiotic sensitivity (\% age) of clinical isolates of $K$. pneumoniae.

\begin{tabular}{|lllllll|}
\hline Antibiotic & Pus & Urine & Blood & CSF & Miscellaneous & Mean \\
\hline Imipenem & 82.5 & 72.1 & 84.6 & 94.4 & 66.7 & 81.8 \\
\hline Cefoperazone & 69.3 & 76.6 & 83.1 & 71 & 88.9 & 73.9 \\
\hline Ceftizoxime & 53.9 & 50.6 & 43.1 & 50.4 & 44.4 & 50.8 \\
\hline Ceftriaxone & 47.6 & 53.8 & 40 & 48.6 & 44.4 & 48.7 \\
\hline Cefotaxime & 32.3 & 54.4 & 58.5 & 59.8 & 55.5 & 48.1 \\
\hline Ceftazidime & 30.7 & 52.5 & 55.3 & 64.5 & 33.3 & 47.2 \\
\hline Amikacin & 68.3 & 78.5 & 73.9 & 76.6 & 66.0 & 73.4 \\
\hline Ofloxacin & 66.7 & 62.3 & 89.2 & 86.9 & 55.5 & 72.1 \\
\hline Levofloxacin & 61.9 & 44.3 & 65 & 50.4 & 66.7 & 54.1 \\
\hline Ciprofloxacin & 42.3 & 48.7 & 63.1 & 69.1 & 55.5 & 52.5 \\
\hline Gentamicin & 35.4 & 64.5 & 61.5 & 53.3 & 55.5 & 51.3 \\
\hline Doxycycline & 43.9 & 38.6 & 63.1 & 50.4 & 44.4 & 46 \\
\hline Co-trimoxazole & 11.3 & 9.1 & 30 & 12.5 & 33.3 & 17.8 \\
\hline Ampicillin & 10.6 & 11.4 & 3 & 4.7 & 11.1 & 8.7 \\
\hline
\end{tabular}

Miscellaneous group includes: pleural, peritoneal, synovial fluid and stool samples.

\section{Antimicrobial class wise sensitivity of K. pneumoniae isolates}

Among 3 most commonly used antibiotics class of drugs against $K$. pneumoniae namely cephalosporins, aminoglycosides and quinolones, aminoglycoside and fluoroquinolones class showed almost equal antimicrobial sensitivity and was higher (62\%) as compared with that of cephalosporin class $(55 \%)$ (Table 3).

Table 3: Antibiotic class wise sensitivity (\%age) of K. pneumoniae isolates.

\begin{tabular}{|llll|}
\hline Sample & $\begin{array}{l}\text { Cephalos } \\
\text { porins }\end{array}$ & $\begin{array}{l}\text { Aminoglycosi } \\
\text { des }\end{array}$ & $\begin{array}{l}\text { Fluoroqui } \\
\text { nolones }\end{array}$ \\
\hline Blood & 58.9 & 65 & 68.9 \\
\hline Urine & 61.4 & 72 & 51.9 \\
\hline Pus & 43.6 & 52 & 57 \\
\hline CSF & 56 & 68 & 69.2 \\
\hline Mean & $\mathbf{5 5}$ & $\mathbf{6 2 . 5}$ & $\mathbf{6 2}$ \\
\hline
\end{tabular}

Cephalosporins include: Cefoperazone, Ceftriaxone,

Ceftazidime, Cefotaxime, Ceftizoxime

Aminoglycosides include: Amikacin, Gentamicin

Quinolones include: Ofloxacin, Levofloxacin, Ciprofloxacin

\section{ESBL positive strains}

Ceftazidime resistant $K$. pneumoniae were screened for ESBL enzyme by PCDDT and DDST methods. Out of 257 ceftazidime resistant $K$. pneumoniae about 88 (33\%) and $87(32 \%)$ were found ESBL positive by PCDDT and DDST respectively. Fifty three $(60 \%)$ out of 88 ESBL producing $K$. pneumoniae were from indoor samples whereas only $35(40 \%)$ were from outdoor samples. Majority of indoor ESBL positive isolates were from medical intensive care unit and surgery wards.

\section{DISCUSSION}

The emergence of gram negative bacterial species with acquired resistance to various broad spectrum beta lactams is becoming a worldwide clinical problem. $K$. pneumoniae did not show $100 \%$ sensitivity to any of the antimicrobial used in the present study. The sensitivity pattern shown was in decreasing order to imipenem, cefoperazone, amikacin, ofloxacin, levofloxacin, ciprofloxacin, gentamicin, ceftizoxime, ceftriaxone, cefotaxime and ceftazidime respectively. Overall antimicrobial group wise mean sensitivity to cephalosporins (55\%) was less than aminoglycosides $(62.5 \%)$ and quinolones $(62 \%)$. Resistance against third generation cephalosporins in present study highlights the most alarming situation of highly diverse antibiotic resistance rate. This can pose serious negative impact in low economy country like India where infectious diseases hold a major health challenge. Overuse of ceftriaxone, cefotaxime, ceftazidime and ceftizoxime has been revealed in the present study this may be associated with development of resistance to $\beta$-lactam antibiotics as reported earlier. ${ }^{12}$ To explore cephalosporin resistance $K$. pneumoniae were tested for ESBL production by two methods. About $33 \%$ of the ceftazidime resistant $K$. pneumoniae were found to produce ESBL by PCDDT and $32 \%$ by DDST. Similar trend was observed in study conducted at other tertiary care hospital. ${ }^{13}$ The PCDDT test was found to be an inexpensive, simple and more sensitive alternative, for the detection of ESBL than DDST which is in accordance with earlier reports. ${ }^{14}$ Prevalence of ESBL production is the most important reason for resistance against novel cephalosporins. As emphasized by various authors prevalence of ESBL positive strain is reported in several regions of India and it varied from one hospital in particular region to another. ${ }^{15-17}$ Wide spread use of third generation cephalosporins causing mutation in genes producing 
enzymes and ESBL has been produced by mutation in TEM1, TEM2, SHV1 in $K$. pneumoniae. ${ }^{18}$ Routine testing for these gene might help in prevention of spread as well as colonization of patients hospitalized for more than 10 days by ESBL positive strains. ${ }^{19}$

Antimicrobial susceptibility to cefoperazone (74\%) was higher as compared to other cephalosporins might be due to its limited use and different chemical structure so it is likely that it is not hydrolysed by ESBL as reported earlier. $^{20}$ The other causes for resistance against $K$. pneumoniae among different third generation might be due to production of Amp $\mathrm{C}$ beta lactamases ${ }^{21}$, production of porins ${ }^{22}$ or some other unknown mechanism. Therefore tests to detect these should be performed on routine basis.

In the present study, high resistance to other drug classes like aminoglycosides, quinolones may be due to plasmid responsible for ESBL production which frequently carry gene encoding resistance to other antibiotic so the options for treatment of ESBL producing organism is very limited. Since these plasmids are easily transmitted among different members of the Enterobacteriaceae, accumulation of resistance genes results in strains which contain multi-resistant plasmids. $^{23}$

Even years after discontinuation of ceftazidime and other extended-spectrum cephalosporins, continued colonization of patients by ESBL-producing Klebsiella strains has been observed. ${ }^{24}$ Recently the use of antibiotics from the class carbapenems as last resort drugs for treating infections due to ESBL-producing organisms has increased. In this study $82 \%$ of $K$. pneumoniae strains were found to be sensitive to imipenem. The increased resistance to carbapenems is reported due to production of Klebsiella pneumoniae carbapenemase (KPC) ${ }^{25}$ an enzyme which hydrolyses carbapenems and will have a serious threat to public health in society. There is need of special laboratory standard techniques to screen KPC as it cannot be detected by routine laboratory methods.

Due to rapid emergence of multidrug resistant organisms, the therapeutic options are becoming limited therefore; in the near future an urgent need for implementation of strict hospital infection control measures to prevent the nosocomial spread of drug resistant $K$. pneumoniae is needed. These include strict adherence to basic epidemiological standards for maintenance and care of urinary catheters, tracheostomies, wounds along with good hand-washing practices ${ }^{26}$, regulation of antibiotic use in the hospital to prevent misuse and overuse of antibiotics and to collect nosocomial infection surveillance data. Hospital infection prevention and control programmes led in the past have resulted in considerable improvements in the management and control of these infections. ${ }^{27}$

\section{CONCLUSION}

This study has shown that prevalence of ESBL producing $K$. pneumoniae is the most important reason for increased resistance against third generation cephalosporins. Findings of this single centre study give an idea of the increasing threat of resistance around a tertiary care hospital which cannot be generalized in larger perspective. Due to cost factors genetic studies are not feasible with the large number of isolates. Routine detection of ESBL-producing microorganisms is required to be done by each laboratory to control the spread of these infections and also to institute proper therapeutic strategies that ensure reduced patient stay, morbidity and cost per day in the hospital.

\section{Funding: No funding sources \\ Competing interests: There are no competing interests to declare}

\section{REFERENCES}

1. Podschun R, Ullmann U. Klebsiella spp. as Nosocomial Pathogens: Epidemiology, Taxonomy, Typing Methods, and Pathogenicity Factors. Clin Microbiol Rev 1998;11:589-603.

2. Willemsen I, Elberts S, Verhulst C, Rwijnsburger M, Filus M, Savelkoul P, et al. Highly resistant gram negative microorganisms: incidence, density and occurrence of nosocomial transmission (TRIANGe Study). Infect Control Hosp Epidemiol 2011;32:33141.

3. Roussel-Delvallez M, Wallet F, et al. Bactericidal activity of three beta lactams alone or in combination with a beta-lactamase inhibitor and two aminoglycosides against Klebsiella pneumoniae harbouring extended spectrum beta lactamases. Clin Microbiol Infect 1988;4:570-6.

4. Lee $\mathrm{CH}$, Su LH, et al. Treatment of ESBL-producing Klebsiella pneumoniae bacteraemia with carbapenems or flomoxef: a retrospective study and laboratory analysis of the isolates. J Antimicrob Chemother 2006;58:1074-7.

5. Pound MW, Fulton KB. Successful treatment of Klebsiella rhinoscleromatis bacteremia with levofloxacin. Pharmacotherapy 2007;27:161-3.

6. Burwen DR, Banerjee SN, Gaynes RP. Ceftazidime resistance among selected nosocomial gram-negative bacilli in the United States. J Infect Dis 1994;170:1622-5.

7. Philippon A, Labia R. Extended spectrum betalactamases. Antimicrob Agents Chemother 1989;33:1131-6.

8. Collee JG, Miles RB, Watt B. Test for identification of bacteria. In Collee JG, Fraser AG, Marimion BP Simmons A, editors. Mackie and McCartney Practical Medical Microbiology: 14th ed. Newyork: Churchill Livingstone; 1996:131-49.

9. Bauer AW, Kirby WM, Sherris JC, Turck M. Antibiotic susceptibility testing by a standardized single disk method. Am J Clin Pathol 1966;36:49396. 
10. National Committee for Clinical Laboratory Standards. Methods for Antimicrobial disc diffusion tests. Approved standard M2-M9, 9th ed. Wayne, Pa. Clinical Laboratory Standards Institute; 2006.

11. Manchanda V, Singh NP, Goyal R, Kumar A, Thukral SS. Phenotypic characteristics of clinical isolates of Klebsiella pneumoniae and evaluation of available techniques for detection of extended spectrum betalactamases. Indian J Med Res 2005;122:330-7.

12. Jarlier V, Nicolas MH, Fournier G, Philippon A. Extended broad-spectrum beta-lactamases conferring transferable resistance to newer beta-lactam agents in Enterobacteriaceae: hospital prevalence and susceptibility patterns. Rev Infect Dis1988;10:867-78.

13. Shukla I, Tiwari R, Agrawal M. Prevalence of extended spectrum $\beta$-lactamasee producing Klebsiella pneumoniae in a tertiary care hospital. Indian $\mathrm{J}$ Med Microbiol 2004;22:87-91.

14. Dalela G. Prevalence of Extended Spectrum Beta Lactamases (ESBL) Producer among Gram negative bacilli from various clinical isolates in a tertiary care hospital at Jhalawar, Rajasthan, India. J Clin Diagn Res 2012;6:182-7.

15. Subha A, Ananthan S. Extended spectrum beta lactamases (ESBLs) mediated resistance to third generation cephalosporins among Klebsiella pneumonia in Chennai. Indian $\mathbf{J}$ Med Microbiol 2002;20:92-5.

16. Hansotia JB, Agarwal V, Pathak AA, Saoji AM. Extended spectrum $\beta$-lactamase mediated resistance to third generation cephalosporins in Klebsiella pneumoniae in Nagpur, central India. Indian J Med Res 1997;105:158-61.

17. Babypadmini S, Appalaraju B. Extended spectrum lactamases in urinary isolates of escherichia coli and klebsiella pneumoniae - Prevalence and susceptibility pattern in a tertiary care hospital. Indian $\mathbf{J}$ Med Microbiol 2004;22:172-4.

18. Du Bois SK, Marriott MS, Amyes SG. TEM-1 and SHV derived extended spectrum beta lactamases: relationship between selection, structure and function. J Antimicrob Chemother 1995;35:7-22.

19. Asensio A, Oliver A, Gonzalez-Diego P, Baquero F, Perez-Diaz JC, Ros P, et al. Outbreak of multiresistant Klebsiella pneumoniae strain in an intensive care unit: antibiotic use as risk factor for colonization and infection. Clin Infect Dis 2003;30:55-60.

20. Hardman JG, Limbird LE, Goodman LS, Gilman A. Goodman Gilman's the Pharmacological Basis of Therapeutics. 12th ed. New York, N.Y.: The McGraw Hills Companies, Inc.

21. Philippon A, Arlet G, Jacoby GA. Plasmiddetermined AmpC-type beta-lactamases. Antimicrob Agents Chemother 2002;46:1-11.

22. Sureda LC, Juan C, Sanchez AD, Alberti S. Role of Klebsiella pneumoniae LamB Porin in Antimicrobial Resistance. Antimicrob Agents Chemother 2011;55:1803-18.

23. Payne DJ, Woodford N, Amyes SG. Charactrization of the plasmid mediated beta lactamase BIL-1. J Antimicrob Chemother 1992;30:119-27.

24. Hibbertrogers LCF, Heritage J, Gascoynebinzi DM, Hawkey PM, Todd N, Lewis IJ, Bailey C. Molecular epidemiology of ceftazidime resistant Enterobacteriaceae from patients on a paediatric oncology ward. J Antimicrob Chemother 1995;36:6582.

25. Nordmann P, Cuzon G, Nass T. The real threat of Klebsiella pneumoniae carbapenemase-producing bacteria. Lancet Infect Dis 2009;9:228-36.

26. Montgomerie JZ. Epidemiology of Klebsiella and hospital-associated infections. Rev Infect Dis 1979; 1:736-53.

27. Lucet JC, Chevret S, Decre D, Vanjak D, Macrez A, Bedos JP, et al. Outbreak of multiply resistant enterobacteriaceae in an intensive care unit: epidemiology and risk factors for acquisition. Clin Infect Dis 1996;22:430-6.

doi: 10.5455/2319-2003.ijbcp20130111

Cite this article as: Kothari S, Mishra V, Ranjan N, Singh A. Third generation cephalosporin-resistance in Klebsiella pneumoniae isolates: an emerging threat. Int J Basic Clin Pharmacol 2013;2:56-60. 